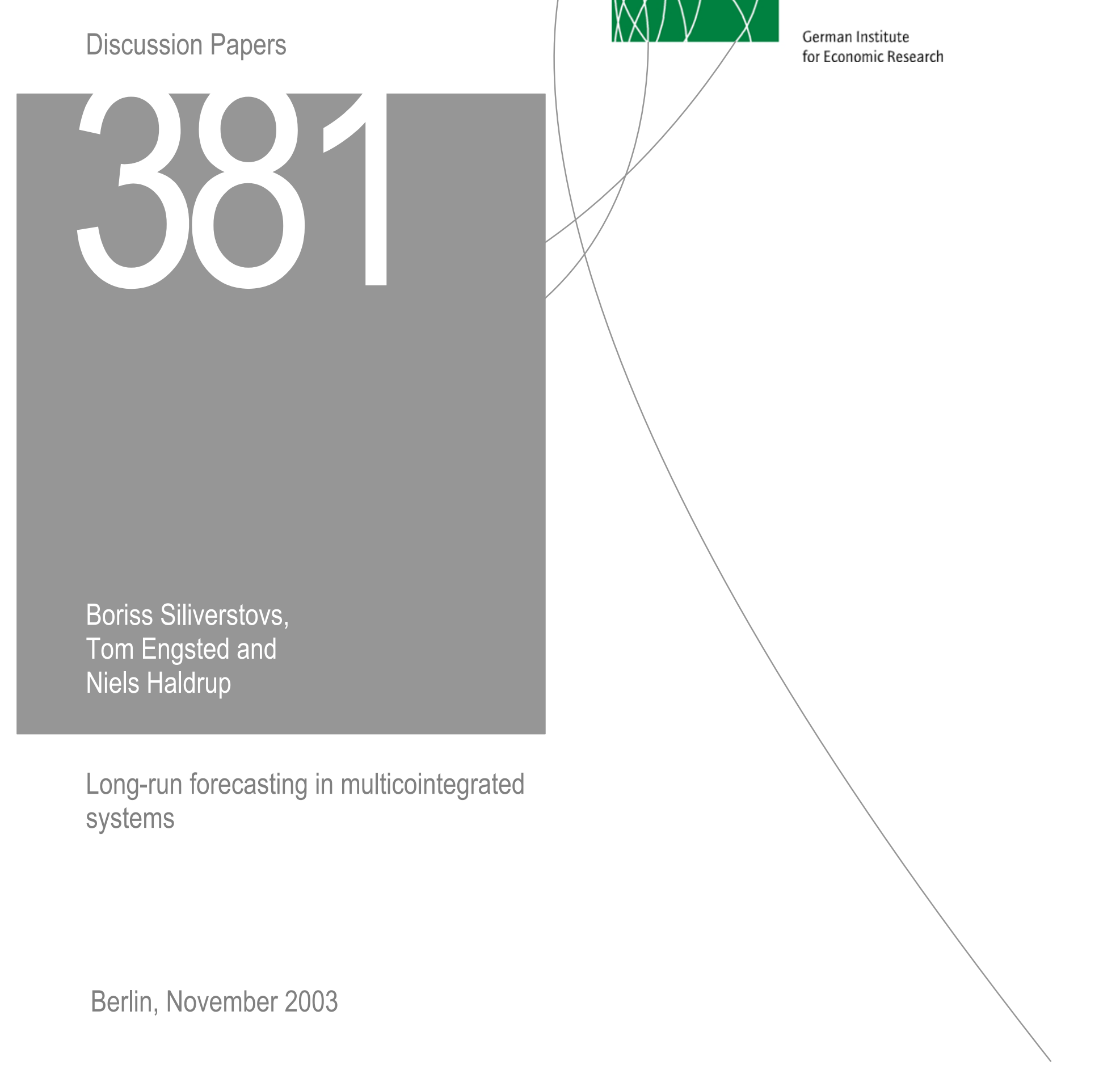


Opinions expressed in this paper are those of the author and do not necessarily reflect views of the Institute.

DIW Berlin

German Institute

for Economic Research

Königin-Luise-Str. 5

14195 Berlin,

Germany

Phone +49-30-897 89-0

Fax $\quad+49-30-89789-200$

www.diw.de

ISSN 1619-4535 


\section{Long-run forecasting}

\section{in multicointegrated systems.*}

$\begin{array}{ccc}\text { Boriss Siliverstovs** } & \text { Tom Engsted } & \text { Niels Haldrup } \\ \text { DIW Berlin } & \text { Department of Finance } & \text { Department of Economics } \\ & \text { The Aarhus School of Business } & \text { University of Aarhus }\end{array}$

September 25, 2003

\footnotetext{
*For constructive criticism the authors would like to thank Hans Christian Kongsted, Philip Hans Franses, and Allan Würtz, the journal departmental editor Allan Timmermann, two anonymous referees, as well as seminar participants at the University of Aarhus, University of Southampton, the 22nd International Symposium on Forecasting in Dublin, and the "Common Features in Rio" conference in Rio de Janeiro.

**Boriss Siliverstovs, DIW Berlin, Königin-Luise Straße 5, 14195 Berlin, Germany, e-mail: bsiliverstovs@diw.de

Tom Engsted, The Aarhus School of Business, Department of Finance, Fuglesangs Allé 4, DK-8210 Aarhus V, Denmark,

e-mail: tom@asb.dk

Niels Haldrup, University of Aarhus, Department of Economics, Building 322, DK-8000 Aarhus C, Denmark,

e-mail: nhaldrup@econ.au.dk
} 


\begin{abstract}
We extend the analysis of Christoffersen and Diebold (1998) on long-run forecasting in cointegrated systems to multicointegrated systems. For the forecast evaluation we consider several loss functions, each of which has a particular interpretation in the context of stock-flow models where multicointegration typically occurs. A loss function based on a standard mean square forecast error (MSFE) criterion focuses on the forecast errors of the flow variables alone. Likewise, a loss function based on the triangular representation of cointegrated systems (suggested by Christoffersen and Diebold) considers forecast errors associated with changes in both stock (modelled through the cointegrating restrictions) and flow variables. We suggest a new loss function which is based on the triangular representation of multicointegrated systems which further penalizes deviations from the long-run relationship between the levels of stock and flow variables as well as changes in the flow variables. Among other things, we show that if one is concerned with all possible long-run relations between stock and flow variables, this new loss function entails high and increasing forecasting gains compared to both the standard MSFE criterion and Christoffersen and Diebold's criterion. The paper demonstrates the importance of carefully selecting loss functions in forecast evaluation of models involving stock and flow variables.
\end{abstract}

Keywords: Multicointegration, Forecasting, Loss function, VAR models.

JEL Classification Codes: C32, C53. 


\section{Introduction}

Assessing the forecasting performance of econometric models is an important ingredient in model evaluation. In multivariate models containing non-stationary variables, cointegration may be thought to play a key role in assessing forecasting ability, especially over long horizons, because cointegration captures the long-run comovement of variables. Several studies have investigated the forecasting properties of cointegrated models. Engle and Yoo (1987) make a small Monte Carlo study where they compare mean-squared forecast errors from a VAR in levels, which does not impose cointegration, to forecasts from a correctly specified error-correction model (ECM), which does impose cointegration, and they find that longer-run forecasts from the ECM are more accurate. This result supports the above intuition that imposing cointegration gives better long-horizon forecasts for variables that are tied together in the long run. However, subsequent research has somewhat questioned and modified this - at first glance appealing - conclusion.

According to Christoffersen and Diebold (1998), the doubts on the usefulness of cointegrating restrictions on the long-run forecasts are related to the following conjecture: The improved predictive power of cointegrating systems comes from the fact that deviations from the cointegrating relations tend to be eliminated. Thus, these deviations contain useful information on the likely future evolution of the cointegrated system which can be exploited to produce superior forecasts when compared to those made from models that omit cointegrating restrictions. However, since the long-run forecast of the cointegrating term is always zero, this information is only likely to be effective when focus lies on producing short-run forecasts. Hence, at least from this point of view, the usefulness of imposing cointegrating relations for producing long-run superior forecasts can be questioned.

Clements and Hendry (1995) compare mean-squared error forecasts from a correctly specified ECM to forecasts from both an unrestricted VAR in levels and a misspecified VAR in first-differences (DVAR) omitting cointegrating restrictions present amongst the variables. They find that the forecasting superiority of the model that correctly imposes the cointegrating restrictions crucially depends upon whether the forecasts are for the levels of the variables, their first-differences, or the cointegrating relationship 
between the variables. They show that this difference in ranking for alternative yet isomorphic representations of the variables is due to the mean-squared forecast error (MSFE) criterion not being invariant to nonsingular, scale-preserving linear transformations of the model. In particular, they show that forecasts from the ECM model are not superior to those made from the DVAR model but at the shortest forecast horizons when first-differences of I(1) variables are forecasted.

Christoffersen and Diebold (1998) compare mean-squared error forecasts of the levels of I(1) variables from a true cointegrated VAR to forecasts from correctly specified univariate representations, and similarly they find that imposing cointegration does not improve long-horizon forecast accuracy. Thus, it appears that the simple univariate forecasts are just as accurate as the multivariate forecasts when judged using the loss function based on the MSFE criterion. They argue that this apparent paradox is caused by the standard MSFE criterion failing to value the long-run forecasts' hanging together correctly. Long-horizon forecasts from the cointegrated VAR always satisfy the cointegrating restrictions exactly, whereas the long-horizon forecasts from the univariate models do so only on average, but this distinction is ignored in the MSFE criterion. Christoffersen and Diebold suggest an alternative criterion that explicitly accounts for this feature. The criterion is based on the triangular representation of cointegrated systems (see Campbell and Shiller, 1987, and Phillips, 1991). The virtue of this criterion is that it assesses forecast accuracy in the conventional "small MSFE" sense, but at the same time it makes full use of the information in the cointegrating relationships amongst the variables. Using this new forecast criterion, they indeed find that at long horizons the forecasts from the cointegrated VAR are superior to the univariate forecasts. Christoffersen and Diebold (1998) demonstrate that the reason for Engle and Yoo's (1987) Monte Carlo experiment to turn out favorable to a model with cointegrating restrictions is not due to the fact that such long-run relations are imposed but rather that the correct number of unit roots is imposed.

The purpose of the present paper is twofold. First, we extend the analysis of Christoffersen and Diebold to the case where the variables under study not only obey cointegrating relationships, but also obey certain multicointegrating restrictions. The concept of multicointegration was originally defined by Granger and Lee $(1989,1991)$ and refers to the case where the underlying I(1) variables are cointegrated 
in the usual sense and where, in addition, the cumulated cointegration errors cointegrate with the original I(1) variables. Thus, essentially there are two levels of cointegration amongst the variables and hence a common feature in the form of a stochastic trend will exist at different levels of the multiple time series.

Multicointegration is a very convenient way of modeling the interactions between stock and flow variables. Granger and Lee consider the case where the two I(1) flow variables production, $y_{t}$, and sales, $x_{t}$, cointegrate, such that inventory investments, $s_{t}$, are stationary, $s_{t} \equiv y_{t}-\beta x_{t} \sim \mathrm{I}(0)$, but where the cumulation of inventory investment, $I_{t} \equiv \Sigma_{j=1}^{t} s_{j}$, i.e. the level of inventories (which is then an I(1) stock variable), in turn cointegrates with either $y_{t}$ or $x_{t}$, or both of them. Another example, analyzed by Lee (1992) and Engsted and Haldrup (1999), is where $y_{t}$ is new housing units started, $x_{t}$ is new housing units completed, $s_{t}$ is uncompleted starts, and hence $I_{t}$ is housing units under construction. Leachman (1996), and Leachman and Francis (2000) provide examples of multicointegrated systems with government revenues and expenditures, and a country's exports and imports, respectively. Here the stock variable is defined as the government debt and the country's external debt, such that each variable is the cumulated series of past government and trade deficits, respectively. Yet another example is provided by Siliverstovs (2001) who analyzes consumption and income, and where cumulated savings (i.e. the cumulation of the cointegrating relationship between income and consumption) constitutes wealth, which further cointegrates with consumption and income.

We investigate how the presence of multicointegration affects long-run forecasting comparisons. In particular, we set up a model that contains both cointegrating and multicointegrating restrictions, and we examine how forecasts from this multicointegrated system compare to univariate forecasts. The comparison is done in terms of the ratio of the (trace) mean-squared forecast errors, but we follow Christoffersen and Diebold (1998) in using both a standard loss function and a loss function based on the triangular representation of the cointegrated system. For a model with multicointegrating restrictions the standard trace mean-squared forecast error criterion entails a loss function that penalizes forecast errors associated with the levels of flow variables whereas the loss function associated with the triangular representation penalizes forecast errors of changes in both the flow and the stock variables. 
As the second purpose of the paper, we are concerned with the fact that, when the loss function of Christoffersen and Diebold (1998) is applied to the multicointegrated systems, it focuses exclusively on the maintenance of the cointegrating restrictions while ignoring multicointegrating restrictions present in the data. This corresponds to ignoring how the levels of both stock and flow variables are related. To this end, we propose a new loss function that is based on the triangular representation of the multicointegrating variables. The distinctive feature of the suggested loss function is that it explicitly acknowledges the maintenance of the multicointegrating restrictions in the data. Moreover, we argue that this loss function follows naturally from models of optimizing behaviour with proportional, integral, and derivative control mechanisms, see e.g. Phillips (1954, 1957), Holt et al. (1960), Hendry and von Ungern Sternberg (1981), and Engsted and Haldrup (1999), and hence has a theoretical founding known from classical stock-flow models. The implications of using this new loss function in assessing the forecast accuracy between the system and univariate forecasts are also scrutinized.

Our most important results can be summarized as follows. First we find that the general result of Christoffersen and Diebold (1998) derived for a standard cointegration model carries over to multicointegrated models, that is, based on a standard MSFE criterion, long-horizon forecasts of the levels of I(1) (flow) variables from the multicointegrated system are found not to be superior to simple univariate forecasts. However, based on the triangular MSFE criterion (accounting for changes in both stocks and flows), the system forecasts are clearly superior to the univariate forecasts. This result demonstrates that as long as the comparison is between the standard MSFE loss function and the triangular MSFE loss function, multicointegration will have no influence on the conclusions drawn by Christoffersen and Diebold. Hence, if the loss function reflects changes in the flow variables, or changes in both the flow and stock variables, then there is really no new insights to be gained from multicointegration in terms of the forecasting properties. However, in stock-flow models one will typically prefer a loss function that also values forecast errors associated with the linkage between the levels of stock and flow variables. Our suggested loss function is doing just that. As a second important result, it is shown that our loss function reflects increasing forecasting gains (for the forecast horizon tending to infinity) when mean squared 
forecast errors from a multicointegrated system are compared to those of univariate forecasts. These results illustrate the importance of carefully selecting loss functions for systems involving stock and flow variables.

In order to make our main points as clear as possible we make a number of simplifications throughout the article. First, we do not discuss estimation and testing. Testing for multicointegration and estimation of models with multicointegrating restrictions are most naturally conducted within an I(2) cointegration framework, see Engsted, Gonzalo and Haldrup (1997), Haldrup (1998), Engsted and Johansen (1999), and Engsted and Haldrup (1999). However, since our primary interest is on the particular dynamic characteristics of multicointegration with respect to forecasting, we abstract from estimation issues and hence assume known parameters. Second, in order to ease the exposition we employ the simplest model with relevant multicointegrating restrictions: a bivariate, low-order model with no deterministic terms. Our bivariate setup is further motivated by the fact that all applications of multicointegration in the literature have been performed for systems of just two variables. Third, while we consider a number of different loss functions to evaluate the forecasts, all the forecasts considered are calculated using the traditional mean squared forecast error criterion (i.e. the forecasts are the conditional means). Thus, we do not consider extensions in the form of Clements and Hendry's (1993) Generalized Forecast Error Second Moment (GFESM) measure, or linear and asymmetric loss functions, as in e.g. Basu and Markov (2003) and Elliot, Komunjer and Timmermann (2003), but we realize that such extensions will be relevant in future research. Finally, we do not investigate the consequences of forecasting with misspecified models. Our primary focus is on the choice of loss function when a forecaster cares about all possible long-run relations amongst stock and flow variables, and in so doing we follow Christoffersen and Diebold (1998) in comparing only forecasts from systems with all long-run relationships imposed to forecasts from correctly specified univariate representations.

The rest of the paper is organized as follows. In Section 2 we set up the multicointegrated systems used in the subsequent analysis. Also, we derive the corresponding univariate representations of the system variables. Section 3 derives the expressions for system and univariate forecasts and the associated 
forecasting errors. In Section 4 we demonstrate the implications on model ranking using various loss functions and the final section concludes.

\section{Multivariate and univariate representations of the multicoin- tegrating variables}

In this section we define the multicointegrated model and derive the corresponding univariate representations of the system variables.

\subsection{Multicointegrated system.}

Consider the two I(1) flow variables, $x_{t}$ and $y_{t}$, that obey a cointegrating relation

$$
y_{t}-\lambda x_{t} \sim I(0)
$$

such that the cumulated cointegration error

$$
\sum_{j=1}^{t}\left(y_{j}-\lambda x_{j}\right) \sim I(1)
$$

is an I(1) variable by construction. We refer to the system as multicointegrated when there exists a stationary linear combination of the cumulated cointegrating error and the original variables, e.g.

$$
\sum_{j=1}^{t}\left(y_{j}-\lambda x_{j}\right)-\alpha x_{t} \sim I(0) .
$$

As discussed in Granger and Lee $(1989,1991)$, the multicointegrating restrictions are likely to occur in stock-flow models, where both cointegrating relations have an appealing interpretation. The first cointegrating relation (1) is formed between the original flow variables, for example, production and sales, income and expenditures, exports and imports, etc. The second cointegrating relation (2) represents the relation between the cumulated past discrepancies between the flow variables, for instance: the stock of inventories, the stock of wealth, the stock of external debt, and all or some flow variables present in the system. It implies that the equilibrium path of the system is maintained not only through the flow 
variables alone, but also through additional forces tying together the stock and flow series and in so doing providing a second layer of equilibrium.

It is convenient to represent the system of multicointegrating variables in the triangular form

$$
\left[\begin{array}{cc}
(1-L) & 0 \\
-\lambda(1-L)^{-1}-\alpha & (1-L)^{-1}
\end{array}\right]\left[\begin{array}{l}
x_{t} \\
y_{t}
\end{array}\right]=\left[\begin{array}{l}
e_{1 t} \\
e_{2 t}
\end{array}\right],
$$

where $L$ is the lag operator, $(1-L)$ is the difference operator, and $(1-L)^{-1}$ is the summation operator, such that when the latter operator is applied to an I(1) time series the resulting time series is $\mathrm{I}(2)$ by construction, i.e. $(1-L)^{-1} x_{t}=\sum_{j=1}^{t} x_{j}$. For simplicity, it is assumed that the disturbances are uncorrelated at all leads and lags, i.e. $E\left(e_{1 t-j} e_{2 t-i}\right)=0, \forall j \neq i$ for $j=0, \pm 1, \pm 2, \ldots$ and $i=0, \pm 1, \pm 2, \ldots$, and the variances of the disturbances $e_{1 t}$ and $e_{2 t}$ are given by $\sigma_{1}^{2}$ and $\sigma_{2}^{2}$, respectively, for all $t$. Hence $x_{t}$ is considered a strictly exogenous variable.

If we denote the generated $\mathrm{I}(2)$ variables by capital letters, i.e. $Y_{t}=\sum_{j=1}^{t} y_{j}$ and $X_{t}=\sum_{j=1}^{t} x_{j}$, then the system can be written

$$
\begin{aligned}
\Delta x_{t} & =e_{1 t} \\
Y_{t} & =\lambda X_{t}+\alpha x_{t}+e_{2 t} .
\end{aligned}
$$

Observe that it closely resembles the so called polynomially cointegrating system where original I(2) variables cointegrate with their own first differences, see Rahbek, Kongsted, and Jørgensen (1999), and Banerjee, Cockerell, and Russell (2001) for examples. ${ }^{1}$

Below we provide two equivalent representations of the system in (3). The Vector Error-Correction model (VECM) can be represented as follows

$$
\left[\begin{array}{c}
\Delta x_{t} \\
\Delta y_{t}
\end{array}\right]=\left[\begin{array}{c}
0 \\
-1
\end{array}\right]\left[y_{t-1}-\lambda x_{t-1}\right]+\left[\begin{array}{c}
0 \\
-1
\end{array}\right]\left[Y_{t-1}-\lambda X_{t-1}-\alpha x_{t-1}\right]+\left[\begin{array}{c}
e_{1 t} \\
(\lambda+\alpha) e_{1 t}+e_{2 t}
\end{array}\right] .
$$

As seen, the VECM explicitly incorporates both cointegration levels, see equations (1) and (2), that are present in the multicointegrated system. Alternatively, the multicointegrated system (3) can be given the

\footnotetext{
${ }^{1}$ The only difference between multi- and polynomially cointegrated models is that in the former case the $\mathrm{I}(2)$ variables are generated from the original I(1) variables, whereas in the latter case $\mathrm{I}(2)$ variables are the original time series.
} 
moving-average (MA) representation

$$
\left[\begin{array}{c}
\Delta x_{t} \\
\Delta y_{t}
\end{array}\right]=C(L) e_{t}=\left[\begin{array}{cc}
1 & 0 \\
{[\lambda+(1-L) \alpha]} & (1-L)^{2}
\end{array}\right]\left[\begin{array}{c}
e_{1 t} \\
e_{2 t}
\end{array}\right] .
$$

Granger and Lee (1991) argue that the necessary and sufficient condition for $x_{t}$ and $y_{t}$ to be multicointegrated is that the determinant of $C(L)$ should have a root $(1-L)^{2}$. This condition is clearly satisfied for our simple system.

\subsection{Univariate representations.}

In this section we derive the implied univariate representations for the $\mathrm{I}(1)$ variables $x_{t}$ and $y_{t}$. Of course, for $x_{t}$ the univariate representation is just

$$
x_{t}=x_{t-1}+e_{1 t} .
$$

In deriving the implied univariate representation for $y_{t}$ we follow Christoffersen and Diebold (1998) by matching the autocovariances of the process $\Delta y_{t}$. From the MA-representation of $\Delta y_{t}$ we have

$$
\begin{aligned}
& \Delta y_{t}=[\lambda+(1-L) \alpha] e_{1 t}+(1-L)^{2} e_{2 t}, \\
& y_{t}=y_{t-1}+z_{t},
\end{aligned}
$$

where the process $z_{t}$ corresponds to the $\mathrm{MA}(2)$ process

$$
z_{t}=u_{t}+\theta_{1} u_{t-1}+\theta_{2} u_{t-2}, \quad u_{t} \sim \operatorname{IID}\left(0, \sigma_{u}^{2}\right)
$$

with $\theta_{1}, \theta_{2}$, and $\sigma_{u}^{2}$ being parameters defined in the technical appendix.

\section{Long-run forecasting in multicointegrated systems.}

In this section we derive expressions for forecasts of the levels of $\mathrm{I}(1)$ variables as well as the corresponding forecast errors both from the system and univariate representations. 


\subsection{System forecasts of I(1) variables.}

The MA-representation of the multicointegrating variables (4) allows us to write the future values of the system variables in terms of $x_{t}$ and future innovations $e_{1 t+h}$ and $e_{2 t+h}$

$$
\begin{aligned}
& x_{t+h}=x_{t}+\sum_{i=1}^{h} e_{1 t+i}, \\
& y_{t+h}=\lambda x_{t}+\lambda \sum_{i=1}^{h} e_{1 t+i}+\alpha e_{1 t+h}+\Delta e_{2 t+h} .
\end{aligned}
$$

Correspondingly, the $h$-steps ahead forecasts for the $\mathrm{I}(1)$ variables are given by ${ }^{2}$

$$
\begin{aligned}
\widehat{x}_{t+h} & =x_{t}, \\
\widehat{y}_{t+h} & =\lambda x_{t}
\end{aligned}
$$

for all forecast horizons but $h=1$. In the latter case we have

$$
\begin{aligned}
& \widehat{x}_{t+1}=x_{t} \\
& \widehat{y}_{t+1}=\lambda x_{t}-e_{2 t}=\lambda x_{t}-\left[Y_{t}-\lambda X_{t}-\alpha x_{t}\right] .
\end{aligned}
$$

In particular, observe that the long-run forecasts from the multicointegrated system maintain the cointegrating relation exactly

$$
\widehat{y}_{t+h}=\lambda \widehat{x}_{t+h}, \text { for } h>1 \text {. }
$$

Continuing, the forecast errors are

$$
\begin{gathered}
\widehat{\varepsilon}_{x, t+h}=\sum_{i=1}^{h} e_{1 t+i} \quad \forall h>0, \\
\widehat{\varepsilon}_{y, t+h}= \begin{cases}\lambda e_{1 t+1}+\alpha e_{1 t+1}+e_{2 t+1}=(\lambda+\alpha) e_{1 t+1}+e_{2 t+1} & \text { for } h=1 \\
\lambda \sum_{i=1}^{h} e_{1 t+i}+\alpha e_{1 t+h}+\Delta e_{2 t+h} & \text { for } h>1 .\end{cases}
\end{gathered}
$$

Furthermore, note that the forecast errors and the original system as in (4) follow the same stochastic process, i.e.

$$
\left[\begin{array}{c}
\Delta \widehat{\varepsilon}_{x, t+h} \\
\Delta \widehat{\varepsilon}_{y, t+h}
\end{array}\right]=\left[\begin{array}{cc}
1 & 0 \\
\lambda+\alpha(1-L) & (1-L)^{2}
\end{array}\right]\left[\begin{array}{l}
e_{1 t+h} \\
e_{2 t+h}
\end{array}\right] .
$$

\footnotetext{
${ }^{2}$ Subsequently, "..." will be associated with system forecasts whereas " $\approx$ " signifies forecasts from univariate models.
} 


\subsection{Univariate forecasts of $\mathrm{I}(1)$ variables.}

Next, we turn to forecasting of the $\mathrm{I}(1)$ variables based on the correctly specified implied univariate representations. Future values of $x_{t+h}$ are given in equation (6) above and for $y_{t+h}$

$$
y_{t+h}= \begin{cases}y_{t}+z_{t+1}=y_{t}+u_{t+1}+\theta_{1} u_{t}+\theta_{2} u_{t-1} & h=1 \\ y_{t}+\sum_{i=1}^{h} z_{t+i}=y_{t}+u_{t+1}+\theta_{1} u_{t}+\theta_{2} u_{t-1}+u_{t+2}+\theta_{1} u_{t+1}+\theta_{2} u_{t}+\sum_{i=3}^{h} z_{t+i}, & h>1 .\end{cases}
$$

The corresponding $h$-steps ahead forecasts for I(1) variables can now be derived as follows. The forecast for $x_{t}$ is the same as the system forecast

$$
\widetilde{x}_{t+h}=\widehat{x}_{t+h}=x_{t}
$$

whereas the forecast $\widetilde{y}_{t+h}$ is given by

$$
\widetilde{y}_{t+h}= \begin{cases}y_{t}+\theta_{1} u_{t}+\theta_{2} u_{t-1}, & \text { for } h=1 \\ y_{t}+\theta_{1} u_{t}+\theta_{2} u_{t-1}+\theta_{2} u_{t}=y_{t}+\left(\theta_{1}+\theta_{2}\right) u_{t}+\theta_{2} u_{t-1}, & \text { for } h>1\end{cases}
$$

The forecast error for $x_{t+h}$ reads

$$
\widetilde{\varepsilon}_{x, t+h}=\widehat{\varepsilon}_{x, t+h}=\sum_{i=1}^{h} e_{1 t+i}
$$

The corresponding forecast error $\widetilde{\varepsilon}_{y, t+h}=y_{t+h}-\widetilde{y}_{t+h}$ for $y_{t}$ is

$$
\widetilde{\varepsilon}_{y, t+h}= \begin{cases}u_{t+1}, & \text { for } h=1 \\ u_{t+1}+u_{t+2}+\theta_{1} u_{t+1}+\sum_{i=3}^{h} z_{t+i}= & \\ \left(1+\theta_{1}+\theta_{2}\right) \sum_{i=1}^{h-2} u_{t+i}+\left(1+\theta_{1}\right) u_{t+h-1}+u_{t+h}, & \text { for } h>1 .\end{cases}
$$

\section{Assessing the forecast accuracy.}

We now investigate the implications of using different specifications of the loss functions on model ranking based on the long-run forecasts. Subsequently we explore how the long-run forecasts compare when judged in terms of three different loss functions. The first is the traditional trace MSFE loss function which penalizes forecast errors associated with the flow variables. The second is the triangular trace MSFE loss 
function based on the triangular representation of the standard I(1) cointegrated system as suggested in Christoffersen and Diebold (1998), which in a multicointegrated model corresponds to penalizing loss associated with forecast errors for the changes in the stock variable as well as changes in one of the flow variables. The last loss function we term the extended triangular loss function which is based on the triangular representation of the multicointegrating variables and thus extending Christoffersen and Diebold (1998) to such systems. This loss function explicitly incorporates the linkage between the levels of stock and flow variables.

\subsection{Traditional trace MSFE loss function.}

First we use the trace MSFE criterion to compare the forecast accuracy of the multivariate and univariate forecast representations. The traditional trace MSFE loss function reads

$$
\text { trace MSFE }=\mathrm{E}\left[\left[\begin{array}{c}
v_{1 t+h} \\
v_{2 t+h}
\end{array}\right]^{\prime}\left[\begin{array}{l}
v_{1 t+h} \\
v_{2 t+h}
\end{array}\right]\right],
$$

where $v_{1 t+h}$ and $v_{2 t+h}$ are the forecast errors of the I(1) flow variables. As seen, only the losses associated with flow variables are penalized in this case.

\subsubsection{Trace MSFE for system forecasts.}

Using the expressions for the system forecast errors in (10) and (11) we can calculate the following forecast error variances

$$
\begin{aligned}
& \operatorname{Var}\left(\widehat{\varepsilon}_{x, t+h}\right)=h \sigma_{1}^{2} \sim O(h), \text { for } h>0 \\
& \operatorname{Var}\left(\widehat{\varepsilon}_{y, t+h}\right)= \begin{cases}(\lambda+\alpha)^{2} \sigma_{1}^{2}+\sigma_{2}^{2}, & \text { for } h=1 \\
\lambda^{2} \sigma_{1}^{2} h+\left[(\lambda+\alpha)^{2}-\lambda^{2}\right] \sigma_{1}^{2}+2 \sigma_{2}^{2} \sim O(h), & \text { for } h>1 .\end{cases}
\end{aligned}
$$

Notice that the variance of the system forecast error for $y_{t+h}$ and $x_{t+h}$ is growing of order $O(h)$. Then, for the system forecasts we have

$$
\text { trace } \widehat{M S F} E= \begin{cases}\sigma_{1}^{2}+(\lambda+\alpha)^{2} \sigma_{1}^{2}+\sigma_{2}^{2}, & h=1 \\ \lambda^{2} \sigma_{1}^{2} h+\left[(\lambda+\alpha)^{2}-\lambda^{2}\right] \sigma_{1}^{2}+2 \sigma_{2}^{2}+h \sigma_{1}^{2}, & h>1 .\end{cases}
$$




\subsubsection{Trace MSFE for univariate forecasts.}

Using expressions (13) and (14) we can calculate the variance of the univariate forecast errors

$$
\begin{gathered}
\operatorname{Var}\left(\widetilde{\varepsilon}_{x, t+h}\right)=\operatorname{Var}\left(\widehat{\varepsilon}_{x, t+h}\right)=h \sigma_{1}^{2} \sim O(h) . \\
\operatorname{Var}\left(\widetilde{\varepsilon}_{y, t+h}\right)= \begin{cases}\sigma_{u}^{2}, & \text { for } h=1 \\
{\left[\left(1+\theta_{1}+\theta_{2}\right)^{2}(h-2)+\left(1+\theta_{1}\right)^{2}+1\right] \sigma_{u}^{2}=} & \\
=\lambda^{2} \sigma_{1}^{2}(h-2)+\left[\left(1+\theta_{1}\right)^{2}+1\right] \sigma_{u}^{2} \sim O(h), & \text { for } h>1 .\end{cases}
\end{gathered}
$$

Observe that similar to the system forecast errors the variance of the univariate forecast errors grows of order $O(h)$. As a result we have

$$
\operatorname{trace} \widetilde{M S F} E= \begin{cases}\sigma_{1}^{2}+\sigma_{u}^{2}, & h=1 \\ \lambda^{2} \sigma_{1}^{2}(h-2)+\left[\left(1+\theta_{1}\right)^{2}+1\right] \sigma_{u}^{2}+h \sigma_{1}^{2} \sim O(h), & h>1 .\end{cases}
$$

\subsubsection{Trace MSFE ratio.}

Comparing the forecast accuracy of the system- and univariate models, we get

$$
\frac{\operatorname{trace} \widehat{M S F} E}{\operatorname{trace} \widehat{M S F} E}=\frac{h \sigma_{1}^{2}+\lambda^{2}(h-1) \sigma_{1}^{2}-\lambda^{2} \sigma_{1}^{2}+\left[\left(1+\theta_{1}\right)^{2}+1\right] \sigma_{u}^{2}}{h \sigma_{1}^{2}+\lambda^{2}(h-1) \sigma_{1}^{2}+(\lambda+\alpha)^{2} \sigma_{1}^{2}+2 \sigma_{2}^{2}} \sim \frac{O(h)}{O(h)} \rightarrow 1 .
$$

As seen, for $h \rightarrow \infty$ this ratio approaches 1 since the coefficients to the leading terms both in the nominator and denominator are identical. That is, on the basis of the traditional forecast comparison criterion (trace MSFE ratio) it is impossible to distinguish between the model with imposed multicointegration restrictions and the model that ignores these restrictions completely. Thus, the conclusion of the use of the traditional trace MSFE ratio in assessing long-run system- and univariate forecasts in the multicointegrated systems coincides with that of Christoffersen and Diebold (1998) derived for the standard I(1) cointegrated model.

\subsection{Triangular trace MSFE loss function.}

In this section we investigate the implications of using the loss function suggested in Christoffersen and Diebold (1998) to long-run forecasts of the multicointegrating variables. Recall that this loss function 
has been proposed for evaluating long-run forecasts in the standard I(1) cointegrated system. The main point that we want to make is that the motivation for using Christoffersen and Diebold's loss function in the standard I(1) cointegrated systems carries over to the multicointegrating setup in a straightforward manner. This justifies the use of their loss function in multicointegrated models if the forecast evaluator is not concerned with losses associated with the linkage between the levels of stock and flow variables. This loss function has the interpretation of attaching loss to forecast errors associated with changes in stock and flow variables as opposed to the standard trace MSFE criterion which only accommodates losses associated with forecasting levels of flow variables.

First, it is worthwhile reviewing related results of Christoffersen and Diebold (1998) for the long-run forecasts in standard I(1) cointegrated systems. As discussed above, Christoffersen and Diebold (1998) show that when comparing the forecasting performance of models that impose cointegration and correctly specified univariate models in terms of the MSFE ratio, there are no gains of imposing cointegration except at the shortest forecast horizons. The problem is that the MSFE criterion fails to acknowledge the important distinction between long-run system forecasts and univariate forecasts. That is, the intrinsic feature of the long-run system forecasts is that they preserve the cointegrating relations exactly, whereas the long-run forecasts from the univariate models satisfy the cointegrating relations only on average. As a result, the variance of the cointegrating combination of the system forecast errors will always be smaller than that of the univariate forecast errors.

Therefore, if one can define a loss function which recognizes the distinction between system- and univariate forecasts, then it becomes possible to discriminate between the forecasts made from these models. Christoffersen and Diebold (1998) show that such a loss function can be based on the triangular representation of cointegrating variables, see Campbell and Shiller (1987), and Phillips (1991). In its simplest form a standard cointegrated system for I(1) flow variables reads

$$
\left[\begin{array}{cc}
1-L & 0 \\
-\lambda & 1
\end{array}\right]\left[\begin{array}{l}
z_{1 t} \\
z_{2 t}
\end{array}\right]=\left[\begin{array}{l}
v_{1 t} \\
v_{2 t}
\end{array}\right],
$$

where it is assumed that the disturbance terms are uncorrelated at all leads and lags. The corresponding 
loss function, introduced in Christoffersen and Diebold (1998), looks as follows

$$
\text { trace } \mathrm{MSFE}_{t r i}=\mathrm{E}\left[\left[\begin{array}{c}
v_{1 t+h} \\
v_{2 t+h}
\end{array}\right]^{\prime} K\left[\begin{array}{c}
v_{1 t+h} \\
v_{2 t+h}
\end{array}\right]\right] \text {, where } K=\left[\begin{array}{cc}
1-L & 0 \\
-\lambda & 1
\end{array}\right]^{\prime}\left[\begin{array}{cc}
1-L & 0 \\
-\lambda & 1
\end{array}\right] .
$$

It is instructive to compare this with the traditional MSFE used in other studies, see equation (15), where $K=I$. The trace $\mathrm{MSFE}_{t r i}$ criterion values small forecast errors as does the traditional MSFE criterion, but at the same time it also values maintenance of the cointegrating restrictions amongst the generated forecasts. The forecast accuracy of a given model is judged upon the linear transformations of the corresponding forecast errors $v_{1 t+h}$ and $v_{2 t+h}$ of the I(1) flow variables. Observe that for multicointegrated series the cointegrating combination of the forecast errors $v_{2, t+h}-\lambda v_{1, t+h}$ corresponds to the forecast errors of changes in the stock variable whereas $(1-L) v_{1, t+h}$ is the forecast error of changes in a flow variable.

\subsubsection{Triangular trace MSFE for system forecasts.}

In order to use the triangular trace MSFE criterion we need to compute the variance of the cointegrating combination of the forecast errors. Using expressions (10) and (11), it follows that

$$
\operatorname{Var}\left(\widehat{\varepsilon}_{y, t+h}-\lambda \widehat{\varepsilon}_{x, t+h}\right)= \begin{cases}\alpha^{2} \sigma_{1}^{2}+\sigma_{2}^{2}, & \text { for } h=1 \\ \alpha^{2} \sigma_{1}^{2}+2 \sigma_{2}^{2}, & \text { for } h>1\end{cases}
$$

which is finite for all forecast horizons. Then, using the expression $\operatorname{Var}\left((1-L) \widehat{\varepsilon}_{x, t+h}\right)=\sigma_{1}^{2}$ we can calculate the triangular trace MSFE for the system forecasts

$$
\text { trace } \widehat{\mathrm{MSF}_{t r i}}= \begin{cases}\alpha^{2} \sigma_{1}^{2}+\sigma_{2}^{2}+\sigma_{1}^{2}, & \text { for } h=1 \\ \alpha^{2} \sigma_{1}^{2}+2 \sigma_{2}^{2}+\sigma_{1}^{2}, & \text { for } h>1 .\end{cases}
$$

Observe that in this simple model the trace $\widehat{\mathrm{MSF}} \mathrm{E}_{t r i}$ is the same for all forecast horizons except for $h=1$. The reason for the difference that occurs when $h=1$ can be seen from equations (7) and (8) which show that the multicointegrating term is in the information set for $h=1$ and it has expectation zero for $h>1$. 


\subsubsection{Triangular trace MSFE for univariate forecasts.}

The triangular trace MSFE for univariate forecasts reads

$$
\text { trace } \widetilde{\mathrm{MSFE}_{t r i}}= \begin{cases}\operatorname{Var}\left(\widetilde{\varepsilon}_{y, t+h}\right)-\operatorname{Var}\left(\widehat{\varepsilon}_{y, t+h}\right)+\alpha^{2} \sigma_{1}^{2}+\sigma_{2}^{2}+\sigma_{1}^{2}, & \text { for } h=1 \\ \operatorname{Var}\left(\widetilde{\varepsilon}_{y, t+h}\right)-\operatorname{Var}\left(\widehat{\varepsilon}_{y, t+h}\right)+\alpha^{2} \sigma_{1}^{2}+2 \sigma_{2}^{2}+\sigma_{1}^{2}, & \text { for } h>1\end{cases}
$$

which is finite for all forecast horizons as well due to the fact that the variance of the cointegrating combination of the univariate forecast errors is $O(1)$, see the technical appendix. The expressions for $\operatorname{Var}\left(\widehat{\varepsilon}_{y, t+h}\right)$ and $\operatorname{Var}\left(\widetilde{\varepsilon}_{y, t+h}\right)$ are defined in $(17)$ and (20), respectively.

\subsubsection{Triangular trace MSFE ratio.}

Using expressions (25) and (26) we can now compute the trace MSFE ratio's

$$
\begin{aligned}
& \frac{\text { trace } \widehat{\mathrm{MSFE}_{t r i}^{h=1}}}{\text { trace } \widehat{\mathrm{MSF}} \mathrm{E}_{t r i}^{h=1}}=1+\frac{\operatorname{Var}\left(\widetilde{\varepsilon}_{y, t+h}\right)-\operatorname{Var}\left(\widehat{\varepsilon}_{y, t+h}\right)}{\alpha^{2} \sigma_{1}^{2}+\sigma_{2}^{2}+\sigma_{1}^{2}}>1, \\
& \frac{\text { trace } \widehat{\mathrm{MSF}} \mathrm{E}_{t r i}^{h>1}}{\text { trace } \widehat{\mathrm{MSF}} \mathrm{E}_{t r i}^{h>1}}=1+\frac{\operatorname{Var}\left(\widetilde{\varepsilon}_{y, t+h}\right)-\operatorname{Var}\left(\widehat{\varepsilon}_{y, t+h}\right)}{\alpha^{2} \sigma_{1}^{2}+2 \sigma_{2}^{2}+\sigma_{1}^{2}}>1 .
\end{aligned}
$$

The trace $\mathrm{MSFE}_{t r i}$ ratio is constant and greater than one as the system forecasts based on the full information is more accurate than the univariate forecasts based on the partial information, i.e.

$\left[\operatorname{Var}\left(\widetilde{\varepsilon}_{y, t+h}\right)-\operatorname{Var}\left(\widehat{\varepsilon}_{y, t+h}\right)\right]>0$ for all $h>0$. Expressed in terms of the model parameters, expressions (27) and (28) read

$$
\begin{aligned}
& \frac{\text { trace } \widetilde{\mathrm{MSFE}}_{t r i}^{h=1}}{\text { trace } \widehat{\mathrm{MSFE}_{t r i}^{h=1}}}=\frac{\sigma_{u}^{2}-\lambda^{2} \sigma_{1}^{2}-2 \lambda \alpha \sigma_{1}^{2}+\sigma_{1}^{2}}{\alpha^{2} \sigma_{1}^{2}+\sigma_{2}^{2}+\sigma_{1}^{2}}>1, \\
& \frac{\text { trace } \widehat{\mathrm{MSF}_{t r i}^{h>1}}}{\text { trace } \widehat{\mathrm{MSF}^{h>1}}}=\frac{\left[\left(1+\theta_{1}\right)^{2}+1\right] \sigma_{u}^{2}-2 \lambda^{2} \sigma_{1}^{2}-2 \lambda \alpha \sigma_{1}^{2}+\sigma_{1}^{2}}{\alpha^{2} \sigma_{1}^{2}+2 \sigma_{2}^{2}+\sigma_{1}^{2}}>1 .
\end{aligned}
$$

In summary, several of the results in Christoffersen and Diebold (1998) derived for standard cointegrated systems carry over to models that obey multicointegrating restrictions. First, long-run forecasts generated from the multicointegrated system preserve the cointegrating relations exactly, see (9). Second, the system forecast errors follow the same stochastic process as the original variables, as depicted in (12). Third, the variance of the cointegrating combination of the system forecast errors is finite (see (24)) even 
though the variance of the system forecast errors of the individual variables grow of order $O(h)$, as seen in expressions (16) and (17). Fourth, the variance of the cointegrating combination of the univariate forecast errors is finite too, even though the variance of the univariate forecast errors grows of order $O(h)$, see expressions (19) and (20). Fifth, imposing the multicointegrating restrictions does not lead to improved long-run forecast performance over the univariate models when compared in terms of the ratio of the traditional mean squared forecast error criterion, as shown in (22). Finally, adoption of a loss function based on the triangular representation of the standard I(1) cointegrated system leads to superior ranking of the system forecasts over their univariate competitors, see expressions (27) and (28).

\subsection{An extended triangular trace MSFE loss function.}

The loss function of Christoffersen and Diebold (1998) incorporates only the first layer of cointegration while ignoring the second - the multicointegrating restriction. We now propose a new loss function based on the triangular representation of the multicointegrating system given in equation (3)

$$
\operatorname{trace} \mathrm{MSFE}_{t r i}^{\star}=\mathrm{E}\left[\left[\begin{array}{c}
v_{1 t+h} \\
v_{2 t+h}
\end{array}\right]^{\prime} K^{*}\left[\begin{array}{c}
v_{1 t+h} \\
v_{2 t+h}
\end{array}\right]\right]
$$

with the $K^{*}$ matrix given by

$$
K^{*}=\left[\begin{array}{cc}
(1-L) & 0 \\
-\lambda(1-L)^{-1}-\alpha & (1-L)^{-1}
\end{array}\right]^{\prime}\left[\begin{array}{cc}
(1-L) & 0 \\
-\lambda(1-L)^{-1}-\alpha & (1-L)^{-1}
\end{array}\right]
$$

and $v_{1 t+h}$ and $v_{2 t+h}$ are the forecast errors of the $\mathrm{I}(1)$ flow variables. Again, the suggested loss function can be considered a generalization of the traditional trace MSFE loss function presented in equation (15), where the $K^{*}$ matrix is the identity matrix. The loss function (29) reflects the costs of deviating from the multicointegrating relation and hence explicitly accounts for the fact that the levels of stock and flow variables are directly interrelated ${ }^{3}$. Our proposed loss function has the obvious advantage that it

\footnotetext{
${ }^{3}$ Note that as opposed to the traditional trace MSFE criterion (15), use of the trace $\mathrm{MSFE}_{t r i}^{*}$ criterion (29) as well as the trace $\mathrm{MSFE}_{t r i}$ criterion of Christoffersen and Diebold (1998), (23), requires knowledge about the $(\lambda, \alpha)$ and $\lambda$ parameters, respectively, i.e. the parameters defining the long run relations. In practice, these parameters will most often have to be
} 
incorporates all possible long-run relations between the flow variables $y_{t}$ and $x_{t}$. A more explicit economic motivation for the loss function can be given by reference to Granger and Lee (1990) and Lee (1996), where, in a particular linear quadratic adjustment cost model of optimizing behavior, agents want to predict and minimize losses associated with both a flow-target discrepancy and a stock-target discrepancy in addition to adjustment costs. In the case of production, sales and inventories, for example, firms may have a target for both sales and inventories, and face costs associated with changing production. Thus, discrepancies between the stock and flow variable targets (i.e. the multicointegrating relation) and the differences in the flow variables are explicitly penalized. As seen, this corresponds closely to the losses implied by our $\mathrm{TMSFE}_{t r i}^{*}$ criterion. A behavioral model that can generate multicointegration arises naturally in stockflow models where losses are associated with PID control, that is, control systems with proportional, integral, and derivative control mechanisms also known from control engineering, see e.g. Phillips (1954, 1957), Holt et al. (1960), and Hendry and von Ungern Sternberg (1981).

We now illustrate the implications of using the new loss function on model ranking.

\subsubsection{Trace $\mathrm{MSFE}_{t r i}^{\star}$ for system forecasts.}

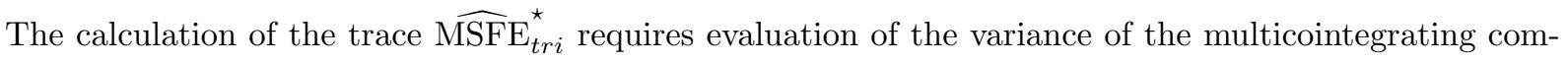
bination of the system forecast errors

$$
(1-L)^{-1} \widehat{\varepsilon}_{y, t+h}-\lambda(1-L)^{-1} \widehat{\varepsilon}_{x, t+h}-\alpha \widehat{\varepsilon}_{x, t+h}=\widehat{\varepsilon}_{Y, t+h}-\lambda \widehat{\varepsilon}_{X, t+h}-\alpha \widehat{\varepsilon}_{x, t+h},
$$

where we have denoted the cumulative forecast errors as $\widehat{\varepsilon}_{X, t+h}$ and $\widehat{\varepsilon}_{Y, t+h}$. These are the forecast errors of the levels of the generated I(2) variables $X_{t+h}$ and $Y_{t+h}$, respectively.

The variance of the multicointegrating combination of the system forecast errors as derived in the technical appendix reads

$$
\operatorname{Var}\left(\widehat{\varepsilon}_{Y, t+h}-\lambda \widehat{\varepsilon}_{X, t+h}-\alpha \widehat{\varepsilon}_{x, t+h}\right)=\sigma_{2}^{2},
$$

estimated. When only the forecast and/or forecast errors are available it may thus be a practical problem to use these criteria without further information. 
which is finite, and for our simple model it is constant for all forecast horizons $h>0$ as there is no shortrun dynamics. In addition, observe that the corresponding forecast error variances of the transformed forecast errors $\operatorname{Var}\left(\widehat{\varepsilon}_{X, t+h}\right)$ and $\operatorname{Var}\left(\widehat{\varepsilon}_{Y, t+h}\right)$ are of the order $O\left(h^{3}\right)$.

The finding of a finite variance of the multicointegrating combination of the forecast errors is similar to that of Christoffersen and Diebold (1998), and Engle and Yoo (1987) for I(1) systems with standard cointegrating restrictions. This is due to the fact that the forecast errors follow the same stochastic process as the forecasted time series, as shown in (12). As a consequence, the forecast errors are integrated of the same order and share the multicointegrating properties of the system dynamics as well.

Combining expression (30) with the expression $\operatorname{Var}\left((1-L) \widehat{\varepsilon}_{x, t+h}\right)=\sigma_{1}^{2}$ we can calculate the trace $\mathrm{MSFE}_{t r i}^{\star}$ for the system forecasts as

$$
\text { trace } \widehat{\mathrm{MSF}} \mathrm{E}_{t r i}^{\star}=\sigma_{2}^{2}+\sigma_{1}^{2}
$$

\subsubsection{Trace $\mathrm{MSFE}_{t r i}^{\star}$ for univariate forecasts.}

Next, we calculate the variance of the multicointegrating combination of the forecast errors from the univariate representation. Straightforward but tedious algebra relegated to the technical appendix yields

$$
\operatorname{Var}\left(\widetilde{\varepsilon}_{Y, t+h}-\lambda \widetilde{\varepsilon}_{X, t+h}-\alpha \widetilde{\varepsilon}_{x, t+h}\right)=\left[\operatorname{Var}\left(\widetilde{\varepsilon}_{Y, t+h}\right)-\operatorname{Var}\left(\widehat{\varepsilon}_{Y, t+h}\right)\right]+\sigma_{2}^{2},
$$

which combined with the result $\operatorname{Var}\left((1-L) \widetilde{\varepsilon}_{x, t+h}\right)=\sigma_{1}^{2}$ yields the following expression for the trace $\mathrm{MSFE}_{t r i}^{\star}$ for the univariate forecasts

$$
\text { trace } \widetilde{\mathrm{MSFE}_{t r i}^{\star}}=\left[\operatorname{Var}\left(\widetilde{\varepsilon}_{Y, t+h}\right)-\operatorname{Var}\left(\widehat{\varepsilon}_{Y, t+h}\right)\right]+\sigma_{2}^{2}+\sigma_{1}^{2} \sim O\left(h^{2}\right) .
$$

Observe that although each of the terms $\operatorname{Var}\left(\widetilde{\varepsilon}_{Y, t+h}\right)$ and $\operatorname{Var}\left(\widehat{\varepsilon}_{Y, t+h}\right)$ are $O\left(h^{3}\right)$, their difference $\left[\operatorname{Var}\left(\widetilde{\varepsilon}_{Y, t+h}\right)-\operatorname{Var}\left(\widehat{\varepsilon}_{Y, t+h}\right)\right]$ is $O\left(h^{2}\right)$. 


\subsubsection{Ratio trace $\mathrm{MSFE}_{t r i}^{\star}$ of the univariate to system forecasts.}

Using equations (31) and (32) we can compute the trace $\mathrm{MSFE}_{t r i}^{\star}$ ratio of the univariate to system forecasts

$$
\frac{\text { trace } \widehat{\mathrm{MSF}_{t r i}^{*}}}{\text { trace } \widehat{\mathrm{MSF}_{t r i}^{\star}}}=\frac{\left[\operatorname{Var}\left(\widetilde{\varepsilon}_{Y, t+h}\right)-\operatorname{Var}\left(\widehat{\varepsilon}_{Y, t+h}\right)\right]+\sigma_{2}^{2}+\sigma_{1}^{2}}{\sigma_{2}^{2}+\sigma_{1}^{2}}=1+\frac{\left[\operatorname{Var}\left(\widetilde{\varepsilon}_{Y, t+h}\right)-\operatorname{Var}\left(\widehat{\varepsilon}_{Y, t+h}\right)\right]}{\sigma_{2}^{2}+\sigma_{1}^{2}}>1 .
$$

Intuitively, this inequality holds as the forecasts that utilize all the information in the system (system forecasts) will produce a smaller forecast error variance than the ones that are based on the partial information (univariate forecasts). It also resembles the trace $\mathrm{MSFE}_{t r i}$ ratio in (27) and (28).

Using these results it is seen that

$$
\frac{\text { trace } \widehat{\mathrm{MSFE}_{t r i}^{\star}}}{\text { trace } \widehat{\mathrm{MSFE}_{\text {tri }}^{\star}}}=\frac{O\left(h^{2}\right)}{O(1)} \rightarrow \infty \text { as } h \rightarrow \infty .
$$

This means that we would prefer the model with multicointegrating restrictions using this criterion.

In fact, there are high (increasing) gains to be achieved in using the new loss function both over the traditional MSFE loss function and the triangular MSFE loss function suggested in Christoffersen and Diebold (1998). The result (33) emphasizes that if in fact the forecast evaluator is concerned with losses associated with the stocks and flows not deviating too much from their steady state level as is done in e.g. inventory models with PID control, then this should be reflected in the loss function. As seen, huge gains can be achieved from the system forecast when compared to using simple univariate forecasts.

\section{Conclusions.}

In this paper we have extended the analysis of Christoffersen and Diebold (1998) to multicointegrated systems. The motivation has been that in multicointegrated systems a complicated dynamic interaction

of flow and stock variables may take place and in forecasting such variables a range of loss functions are available when evaluating and comparing forecasts from different models. Christoffersen and Diebold's analysis can be conducted by assuming multicointegrated series rather than cointegrated series in the usual I(1) sense. When this occurs the variables can be given a particular interpretation. A loss function 
based on a standard trace mean square forecast error criterion corresponds to forecast evaluation where the forecast errors associated with the flow variables enter the loss function. On the other hand, the loss function of Christoffersen and Diebold, based on the triangular representation of cointegrated systems, can be expressed in terms of losses associated with forecast errors of changes in both the flow and stock variables. Although this loss function penalizes deviations from the cointegrating relation only and completely ignores the multicointegrating restrictions, when applied to forecasts from multicointegrated models, it clearly favours those over the univariate model forecasts. Notwithstanding, if a forecaster is concerned with the multicointegrating nature of the forecasted variables a new loss function is required. This function can be derived from the triangular representation of a multicointegrated system and we show that such a function will penalize deviations from a long-run stock and flow relation. In fact, the suggested loss function appears to have huge gains when compared to forecasts of the implied univariate models.

We do not want to take a strong stand upon which loss function to use in practice when evaluating different models. In this paper we have compared model forecasts from a correctly specified univariate model with that of a correctly specified system forecast. In model selection based on forecasting performance, one may prefer choosing a loss function which favors models which incorporate stronger (multicointegrating) restrictions on the variables than models which do not (i.e. the univariate models). Ultimately, however, the loss function to be chosen will reflect the preferences of the analyst.

The paper highlights the importance of carefully selecting loss functions when evaluating forecasts from cointegrated systems, and it shows how different loss functions based on a MSFE criterion help selection of competing models of increasing complexity. Comparing competing models, some of which are potentially incorrectly specified, is a different, though very relevant, issue. Deriving new results for multicointegrated systems along these lines, for instance by extending the work of Clements and Hendry (1995) to multicointegrated systems, is a topic for future research. 


\section{References}

Banerjee, A., L. Cockerell, and B. Russell (2001): “An I(2) Analysis of Inflation and the Markup," Journal of Applied Econometrics, 16(3), 221-40.

Basu, S., And S. Markov (2003): "Loss Function Assumptions in Rational Expectations Tests on Financial Analysts' Earnings Forecasts," Working Paper, Goizueta Business School.

Campbell, J. Y., and R. J. Shiller (1987): "Cointegration and Tests of Present Value Models," Journal of Political Economy, 95, 1052-1088.

Christoffersen, P. F., and F. X. Diebold (1998): "Cointegration and Long-Run Forecasting," Journal of Business and Economic Statistics, 16(4), 450-458.

Clements, M. P., and D. F. Hendry (1993): "On the Limitations of Comparing Mean Square Forecast Errors," Journal of Forecasting, 12, 617-37.

Clements, M. P., And D. F. Hendry (1995): "Forecasting in Cointegrating Systems," Journal of Applied Econometrics, 10(2), 127-146.

Elliot, G., I. Komunjer, and A. G. Timmermann (2003): "Estimating Loss Function Parameters," CEPR Discussion Paper No. 3821.

Engle, R. F., And B. S. Yoo (1987): "Forecasting and Testing in Co-Integrated Systems," Journal of Econometrics, 35, 143-159.

Engsted, T., J. Gonzalo, And N. Haldrup (1997): "Testing for Multicointegration," Economics Letters, 56, 259-266.

Engsted, T., And N. Haldrup (1999): "Multicointegration in Stock-Flow Models," Oxford Bulletin of Economics and Statistics, 61, 237-254. 
Engsted, T., And S. Johansen (1999): "Granger's Representation Theorem and Multicointegration," in Cointegration, Causality and Forecasting, Festschrift in Honour of Clive Granger, ed. by R. Engle, and H. White, Oxford. Oxford University Press.

Granger, C. W. J., and T. H. Lee (1989): "Investigation of Production, Sales and Inventory Relations Using Multicointegration and Non-Symmetric Error Correction Models," Journal of Applied Econometrics, 4, S145-S159.

Granger, C. W. J., And T. H. Lee (1991): "Multicointegration," in Long-Run Economic Relationships. Reading in Cointegration, ed. by R. F. Engle, and C. W. J. Granger, Advanced Texts in Econometrics, Oxford. Oxford University Press.

Haldrup, N. (1998): “An Econometric Analysis of I(2) Variables," Journal of Economic Surveys, 12(5), 595-650.

Hendry, D. F., And T. von Ungern-Sternberg (1981): "Liquidity and Inflation Effects on Consumers' Expenditure," in Essay in the Theory and Measurement of Consumers' Behaviour, ed. by A. S. Deaton, Cambridge. Cambridge University Press.

Holt, C. C., F. Modigliani, J. F. Muth, and H. Simon (1960): Planning Production, Inventories, and Work Force. Prentice Hall, Edgewood Cliffs.

Leachman, L. L. (1996): "New Evidence on the Ricardian Equivalence Theorem: A Multicointegration Approach," Applied Economics, 28, 695-704.

Leachman, L. L., And B. B. Francis (2000): "Multicointegration Analysis of the Sustainability of Foreign Debt," Journal of Macroeconomics, 22(2), 207-27.

LeE, T. H. (1992): "Stock-Flow Relationships in US Housing Construction," Oxford Bulletin of Economics and Statistics, 54, 419-430.

(1996): “Stock Adjustment for Multicointegrated Series," Empirical Economics, 21, 63-639. 
Phillips, A. W. (1954): "Stabilization Policy in the Closed Economy," The Economic Journal, 64, $290-323$.

(1957): "Stabilization Policy and the Time Form of Lagged Responses," The Economic Journal, $67,265-77$.

Phillips, P. C. B. (1991): "Optimal Inference in Cointegrating Systems," Econometrica, 59, 283-306.

Rahbek, A., H. . C. Kongsted, and C. Jørgensen (1999): "Trend-Stationarity in the I(2) Cointegration Model," Journal of Econometrics, 90, 265-289.

Siliverstovs, B. (2001): "Multicointegration in US Consumption Data," Aarhus University, Department of Economics, Working paper 2001-6.

\section{A Technical Appendix.}

\section{A.1 Derivation of the implied univariate representation for $\Delta y_{t}$, section 2.2.}

From (5) the $\mathrm{MA}(2)$ process for $\Delta y_{t}$ reads

$$
z_{t}=[\lambda+(1-L) \alpha] e_{1 t}+(1-L)^{2} e_{2 t}=u_{t}+\theta_{1} u_{t-1}+\theta_{2} u_{t-2}
$$

The autocovariance structure for $z_{t}$ reads

$$
\begin{aligned}
& \gamma_{z}(0)=\left[(\lambda+\alpha)^{2}+\alpha^{2}\right] \sigma_{1}^{2}+6 \sigma_{2}^{2} \\
& \gamma_{z}(1)=-\alpha(\lambda+\alpha) \sigma_{1}^{2}-4 \sigma_{2}^{2} \\
& \gamma_{z}(2)=\sigma_{2}^{2} \\
& \gamma_{z}(\tau)=0, \quad|\tau| \geq 3 .
\end{aligned}
$$

This is a $\mathrm{MA}(2)$ process with the non-zero first and second autocorrelations. The first autocorrelation 
coefficient is

$$
\begin{aligned}
& \rho_{z}(1)=\frac{-\alpha(\lambda+\alpha) \sigma_{1}^{2}-4 \sigma_{2}^{2}}{\left[(\lambda+\alpha)^{2}+\alpha^{2}\right] \sigma_{1}^{2}+6 \sigma_{2}^{2}}=\frac{-\alpha(\lambda+\alpha) q-4}{\left[(\lambda+\alpha)^{2}+\alpha^{2}\right] q+6} \\
& \rho_{z}(2)=\frac{\sigma_{2}^{2}}{\left[(\lambda+\alpha)^{2}+\alpha^{2}\right] \sigma_{1}^{2}+6 \sigma_{2}^{2}}=\frac{1}{\left[(\lambda+\alpha)^{2}+\alpha^{2}\right] q+6},
\end{aligned}
$$

where

$$
q=\frac{\sigma_{1}^{2}}{\sigma_{2}^{2}}
$$

is the signal-to-noise ratio.

From this we infer values for the parameters $\theta_{1}$ and $\theta_{2}$. By denoting

$$
A=[-\alpha(\lambda+\alpha) q-4] \quad B=\left[(\lambda+\alpha)^{2}+\alpha^{2}\right] q+6
$$

and after some algebra it follows that

$$
\theta_{1}=\frac{\theta_{2}}{\left(1+\theta_{2}\right)} A
$$

and $\theta_{2}$ is one of the roots of the fourth-order polynomial

$$
\theta_{2}^{4}+(2-B) \theta_{2}^{3}+\left(A^{2}-2 B+2\right) \theta_{2}^{2}+(2-B) \theta_{2}+1=0 .
$$

Observe that the coefficient values $\theta_{1}$ and $\theta_{2}$ should satisfy the invertibility conditions for the MA(2) process $z_{t}$. The variance $\sigma_{u}^{2}$ is found from the following expression

$$
\sigma_{u}^{2}=\frac{\left[(\lambda+\alpha)^{2}+\alpha^{2}\right] \sigma_{1}^{2}+6 \sigma_{2}^{2}}{\left(1+\theta_{1}^{2}+\theta_{2}^{2}\right)} \quad \text { or } \quad \sigma_{u}^{2}=\frac{\sigma_{2}^{2}}{\theta_{2}} .
$$

Furthermore, the following relation holds

$$
\lambda^{2} \sigma_{1}^{2}=\left(1+\theta_{1}+\theta_{2}\right)^{2} \sigma_{u}^{2}
$$

\section{A.2 Derivation of the Trace $\mathrm{MSFE}_{t r i}$ for univariate forecasts, section 4.2.2.}

First, we derive the variance of the cointegrating combination of the univariate forecast errors

$$
\operatorname{Var}\left(\widetilde{\varepsilon}_{y, t+h}-\lambda \widetilde{\varepsilon}_{x, t+h}\right)=\operatorname{Var}\left(\widetilde{\varepsilon}_{y, t+h}\right)+\lambda^{2} \operatorname{Var}\left(\widetilde{\varepsilon}_{x, t+h}\right)-2 \lambda \operatorname{cov}\left(\widetilde{\varepsilon}_{y, t+h}, \widetilde{\varepsilon}_{x, t+h}\right),
$$


using expressions (19) and (20) and the following expression for the covariance term

$$
\operatorname{cov}\left(\widetilde{\varepsilon}_{y, t+h}, \widetilde{\varepsilon}_{x, t+h}\right)=\lambda h \sigma_{1}^{2}+\alpha \sigma_{1}^{2} .
$$

The variance of the cointegrating combination of the univariate forecast errors reads

$$
\operatorname{Var}\left(\widetilde{\varepsilon}_{y, t+h}-\lambda \widetilde{\varepsilon}_{x, t+h}\right)= \begin{cases}\sigma_{u}^{2}-\lambda^{2} \sigma_{1}^{2}-2 \lambda \alpha \sigma_{1}^{2}, & \text { for } h=1 \\ -2 \lambda^{2} \sigma_{1}^{2}-2 \lambda \alpha \sigma_{1}^{2}+\left[\left(1+\theta_{1}\right)^{2}+1\right] \sigma_{u}^{2}, & \text { for } h>1,\end{cases}
$$

which is finite for all forecast horizons.

Using expression $\operatorname{Var}\left((1-L) \widehat{\varepsilon}_{x, t+h}\right)=\sigma_{1}^{2}$, we have

$$
\text { trace } \widetilde{\mathrm{MSF}_{t r i}}= \begin{cases}\sigma_{u}^{2}-\lambda^{2} \sigma_{1}^{2}-2 \lambda \alpha \sigma_{1}^{2}+\sigma_{1}^{2}, & \text { for } h=1 \\ {\left[\left(1+\theta_{1}\right)^{2}+1\right] \sigma_{u}^{2}-2 \lambda^{2} \sigma_{1}^{2}-2 \lambda \alpha \sigma_{1}^{2}+\sigma_{1}^{2},} & \text { for } h>1 .\end{cases}
$$

Further simplification results in

$$
\begin{aligned}
& \text { trace } \widetilde{\mathrm{MSF}} \mathrm{E}_{t r i}= \begin{cases}\sigma_{u}^{2}-\lambda^{2} \sigma_{1}^{2}-2 \lambda \alpha \sigma_{1}^{2}-\alpha^{2} \sigma_{1}^{2}+\alpha^{2} \sigma_{1}^{2}+\sigma_{1}^{2}, & \text { for } h=1 \\
{\left[\left(1+\theta_{1}\right)^{2}+1\right] \sigma_{u}^{2}-2 \lambda^{2} \sigma_{1}^{2}-2 \lambda \alpha \sigma_{1}^{2}-\alpha^{2} \sigma_{1}^{2}+\alpha^{2} \sigma_{1}^{2}+\sigma_{1}^{2},} & \text { for } h>1,\end{cases} \\
& \text { trace } \widetilde{\mathrm{MSF}} \mathrm{t}_{t r i}= \begin{cases}\sigma_{u}^{2}-(\lambda+\alpha)^{2} \sigma_{1}^{2}-\sigma_{2}^{2}+\alpha^{2} \sigma_{1}^{2}+\sigma_{2}^{2}+\sigma_{1}^{2}, & \text { for } h=1 \\
{\left[\left(1+\theta_{1}\right)^{2}+1\right] \sigma_{u}^{2}-(\lambda+\alpha)^{2} \sigma_{1}^{2}-\lambda^{2} \sigma_{1}^{2}-2 \sigma_{2}^{2}+2 \sigma_{2}^{2}+\alpha^{2} \sigma_{1}^{2}+\sigma_{1}^{2},} & \text { for } h>1 .\end{cases}
\end{aligned}
$$

Using expressions (17) and (20) we have the following expression for the triangular trace MSFE for univariate forecasts

$$
\text { trace } \widetilde{\mathrm{MSF}} \mathrm{E}_{t r i}= \begin{cases}\operatorname{Var}\left(\widetilde{\varepsilon}_{y, t+h}\right)-\operatorname{Var}\left(\widehat{\varepsilon}_{y, t+h}\right)+\alpha^{2} \sigma_{1}^{2}+\sigma_{2}^{2}+\sigma_{1}^{2}, & \text { for } h=1 \\ \operatorname{Var}\left(\widetilde{\varepsilon}_{y, t+h}\right)-\operatorname{Var}\left(\widehat{\varepsilon}_{y, t+h}\right)+\alpha^{2} \sigma_{1}^{2}+2 \sigma_{2}^{2}+\sigma_{1}^{2}, & \text { for } h>1\end{cases}
$$

which is finite for all forecast horizons as well. 


\section{A.3 Derivation of the Trace $\mathrm{MSFE}_{t r i}^{\star}$ for system forecasts, section 4.3.1.}

Using the results from Section 3 we can compute the following transformations of the system forecast errors

$$
\begin{aligned}
\widehat{\varepsilon}_{x, t+h} & =\sum_{i=1}^{h} e_{1 t+i} \\
\widehat{\varepsilon}_{X, t+h} & =(1-L)^{-1} \widehat{\varepsilon}_{x, t+h}=\sum_{q=1}^{h} \widehat{\varepsilon}_{x, t+q}=\sum_{q=1}^{h} \sum_{i=1}^{q} e_{1 t+i}=\sum_{i=1}^{h}(h+1-i) e_{1 t+i} \\
\widehat{\varepsilon}_{Y, t+h} & =(1-L)^{-1} \widehat{\varepsilon}_{y, t+h}=\sum_{q=1}^{h} \widehat{\varepsilon}_{y, t+q}=\sum_{i=1}^{h}[\lambda(h+1-i)+\alpha] e_{1 t+i}+e_{2 t+h} .
\end{aligned}
$$

The variance of the multicointegrating combination of the forecast errors is

$$
\operatorname{Var}\left(\widehat{\varepsilon}_{Y, t+h}-\lambda \widehat{\varepsilon}_{X, t+h}-\alpha \widehat{\varepsilon}_{x, t+h}\right)=\sigma_{2}^{2},
$$

which is finite, and for our simple model it is constant for all forecast horizons $h>0$ as there is no short-run dynamics.

In addition, observe that the corresponding forecast error variances of the transformed forecast errors are of the order $O\left(h^{3}\right)$ as seen below

$$
\begin{aligned}
& \operatorname{Var}\left(\widehat{\varepsilon}_{X, t+h}\right)=\operatorname{Var}\left(\sum_{q=1}^{h} \sum_{i=1}^{q} e_{1 t+i}\right)=\frac{h(h+1)(2 h+1)}{6} \sigma_{1}^{2} \sim O\left(h^{3}\right) \\
& \operatorname{Var}\left(\widehat{\varepsilon}_{Y, t+h}\right)=\frac{h(h+1)(2 h+1)}{6} \lambda^{2} \sigma_{1}^{2}+2 \alpha \lambda \frac{h(h+1)}{2} \sigma_{1}^{2}+h \alpha^{2} \sigma_{1}^{2}+\sigma_{2}^{2} \sim O\left(h^{3}\right) .
\end{aligned}
$$

Using the expression $\operatorname{Var}\left((1-L) \widehat{\varepsilon}_{x, t+h}\right)=\sigma_{1}^{2}$ we can calculate the trace $\mathrm{MSFE}_{t r i}^{\star}$ for the system forecasts

$$
\text { trace } \widehat{\mathrm{MSF}} \mathrm{E}_{t r i}^{\star}=\sigma_{2}^{2}+\sigma_{1}^{2}
$$




\section{A.4 Derivation of the variance of the multicointegrating combination of uni-} variate forecast errors, section 4.3.2.

The transformation of the forecast errors for $x_{t+h}$ yields the following

$$
\begin{aligned}
\widetilde{\varepsilon}_{x, t+h} & =\sum_{i=1}^{h} e_{1 t+i} \\
\widetilde{\varepsilon}_{X, t+h} & =(1-L)^{-1} \widetilde{\varepsilon}_{x, t+h}=\sum_{q=1}^{h} \sum_{i=1}^{q} e_{1 t+i}=\sum_{i=1}^{h}(h+1-i) e_{1 t+i} .
\end{aligned}
$$

The corresponding transformation of the forecast errors for $y_{t+h}$ reads

$$
\begin{aligned}
\widetilde{\varepsilon}_{Y, t+1} & =(1-L)^{-1} \widetilde{\varepsilon}_{y, t+1}=u_{t+1} \\
\widetilde{\varepsilon}_{Y, t+h} & =(1-L)^{-1} \widetilde{\varepsilon}_{y, t+h}= \\
& =\sum_{i=1}^{h-2}\left\{\left(1+\theta_{1}+\theta_{2}\right)(h-2-i+1)+\left(1+\theta_{1}\right)+1\right\} u_{t+i}+\left(\left(1+\theta_{1}\right)+1\right) u_{t+h-1}+u_{t+h} .
\end{aligned}
$$

Then, we calculate the variance of the multicointegrating combination of the forecast errors from the univariate representation

$$
\begin{aligned}
& \operatorname{Var}\left(\widetilde{\varepsilon}_{Y, t+h}-\lambda \widetilde{\varepsilon}_{X, t+h}-\alpha \widetilde{\varepsilon}_{\Delta X, t+h}\right)= \\
& =\operatorname{Var}\left(\widetilde{\varepsilon}_{Y, t+h}-\lambda \widetilde{\varepsilon}_{X, t+h}\right)+\alpha^{2} \operatorname{Var}\left(\widetilde{\varepsilon}_{\Delta X, t+h}\right)-2 \alpha \operatorname{Cov}\left(\widetilde{\varepsilon}_{Y, t+h}-\lambda \widetilde{\varepsilon}_{X, t+h}, \widetilde{\varepsilon}_{\Delta X, t+h}\right)= \\
& =\operatorname{Var}\left(\widetilde{\varepsilon}_{Y, t+h}\right)+\lambda^{2} \operatorname{Var}\left(\widetilde{\varepsilon}_{X, t+h}\right)-2 \lambda \operatorname{Cov}\left(\widetilde{\varepsilon}_{Y, t+h}, \widetilde{\varepsilon}_{X, t+h}\right)+\alpha^{2} \operatorname{Var}\left(\widetilde{\varepsilon}_{\Delta X, t+h}\right) \\
& -2 \alpha \operatorname{Cov}\left(\widetilde{\varepsilon}_{Y, t+h} \widetilde{\varepsilon}_{\Delta X, t+h}\right)+2 \alpha \lambda \operatorname{Cov}\left(\widetilde{\varepsilon}_{X, t+h}, \widetilde{\varepsilon}_{\Delta X, t+h}\right) .
\end{aligned}
$$

Thus, in order to calculate the variance of the multicointegrating combination of the forecast errors we need to derive the following expressions

$$
\begin{aligned}
\operatorname{Var}\left(\widetilde{\varepsilon}_{Y, t+h}\right)= & \left(1+\theta_{1}+\theta_{2}\right)^{2} \frac{(h-2)(h-2+1)(2(h-2)+1)}{6} \sigma_{u}^{2} \\
& +2\left(\left(1+\theta_{1}\right)+1\right)\left(1+\theta_{1}+\theta_{2}\right) \frac{(h-2)(h-2+1)}{2} \sigma_{u}^{2} \\
& +\left(\left(1+\theta_{1}\right)+1\right)^{2}(h-1) \sigma_{u}^{2}+\sigma_{u}^{2} \\
\operatorname{Var}\left(\widetilde{\varepsilon}_{X, t+h}\right)= & \operatorname{Var}\left(\sum_{q=1}^{h} \sum_{i=1}^{q} e_{1 t+i}\right)=\left(h^{2}+(h-1)^{2}+. .+1\right) \sigma_{1}^{2}=\frac{h(h+1)(2 h+1)}{6} \sigma_{1}^{2} \\
\operatorname{Var}\left(\widetilde{\varepsilon}_{\Delta X, t+h}\right)= & h \sigma_{1}^{2}
\end{aligned}
$$




$$
\begin{aligned}
\operatorname{Cov}\left(\widetilde{\varepsilon}_{Y, t+h}, \widetilde{\varepsilon}_{X, t+h}\right) & =\lambda \frac{h(h+1)(2 h+1)}{6} \sigma_{1}^{2}+\alpha \frac{h(h+1)}{2} \sigma_{1}^{2} \\
\operatorname{Cov}\left(\widetilde{\varepsilon}_{Y, t+h}, \widetilde{\varepsilon}_{\Delta X, t+h}\right) & =\lambda \frac{h(h+1)}{2} \sigma_{1}^{2}+\alpha h \sigma_{1}^{2} \\
\operatorname{Cov}\left(\widetilde{\varepsilon}_{X, t+h}, \widetilde{\varepsilon}_{\Delta X, t+h}\right) & =\operatorname{Cov}\left(\sum_{q=1}^{h} \sum_{i=1}^{q} e_{1 t+i}, \sum_{i=1}^{h} e_{1 t+i}\right)=\frac{h(h+1)}{2} \sigma_{1}^{2}
\end{aligned}
$$

These expressions imply that

$$
\begin{aligned}
& \operatorname{Var}\left(\widetilde{\varepsilon}_{Y, t+h}-\lambda \widetilde{\varepsilon}_{X, t+h}-\alpha \widetilde{\varepsilon}_{\Delta X, t+h}\right)= \\
& =\operatorname{Var}\left(\widetilde{\varepsilon}_{Y, t+h}\right)-\lambda^{2} \frac{h(h+1)(2 h+1)}{6} \sigma_{1}^{2}-2 \alpha \lambda \frac{h(h+1)}{2} \sigma_{1}^{2}-\alpha^{2} h \sigma_{1}^{2}= \\
& =\operatorname{Var}\left(\widetilde{\varepsilon}_{Y, t+h}\right)-\left[\operatorname{Var}\left(\widehat{\varepsilon}_{Y, t+h}\right)-\sigma_{2}^{2}\right]=\left[\operatorname{Var}\left(\widetilde{\varepsilon}_{Y, t+h}\right)-\operatorname{Var}\left(\widehat{\varepsilon}_{Y, t+h}\right)\right]+\sigma_{2}^{2} .
\end{aligned}
$$

Using equation (35), we get the following

$$
\begin{aligned}
& {\left[\operatorname{Var}\left(\widetilde{\varepsilon}_{Y, t+h}\right)-\operatorname{Var}\left(\widehat{\varepsilon}_{Y, t+h}\right)\right]=-h^{2} \lambda^{2} \sigma_{1}^{2}-(h-1)^{2} \lambda^{2} \sigma_{1}^{2}+2\left(2+\theta_{1}\right)\left(1+\theta_{1}+\theta_{2}\right) \frac{(h-2)(h-2+1)}{2} \sigma_{u}^{2}} \\
& +\left(2+\theta_{1}\right)^{2}(h-1) \sigma_{u}^{2}+\sigma_{u}^{2}-2 \alpha \lambda \frac{h(h+1)}{2} \sigma_{1}^{2}-h \alpha^{2} \sigma_{1}^{2}-\sigma_{2}^{2} .
\end{aligned}
$$

As seen, even though each of the expressions $\operatorname{Var}\left(\widetilde{\varepsilon}_{Y, t+h}\right)$ and $\operatorname{Var}\left(\widehat{\varepsilon}_{Y, t+h}\right)$ is $O\left(h^{3}\right)$, their difference $\left[\operatorname{Var}\left(\widetilde{\varepsilon}_{Y, t+h}\right)-\operatorname{Var}\left(\widehat{\varepsilon}_{Y, t+h}\right)\right]$ is $O\left(h^{2}\right)$. 